\title{
THE SPEECH SOUND ERRORS AND LITERACY SKILLS IN CHILDREN WITH OROFACIAL CLEFTS
}

\author{
Arooj Karim Khan, Aasma Yousaf, Sharmeen Aslam Tarer, Rukhsana Kausar* \\ Centre for Clinical Psychology, Lahore Pakistan, *Government College for Women University, Sialkot Pakistan
}

\begin{abstract}
Objective: To investigate the speech sound errors and literacy skills in children with orofacial clefts (cleft palate\& cleft lip and palate).

Study Design: Comparative cross-sectional study.

Place and Duration of Study: Centre for Clinical Psychology, University of the Punjab, Lahore, from Mar 2016 to Feb 2017.

Methodology: A sample of 42 participants (cleft lip \& palate: $n=18$ and cleft palate: $n=24$ ) was collected. Two stage sampling strategy was used. Each child was individually screened through Slosson intelligence test revised checklist of orofacial cleft and diagnostic statistical Manual-V checklist. Then children were provided with assessment measures which included demographic informational questionnaire, community developed VPI Screener, word list for articulation and phonological processes, annual status of education report (ASER) and curriculum-based measurement (Written Expression). Manual SODA (substitution, omission, distortion and addition) analysis was done to know about the type of speech sound errors.

Results: Independent sample t-test was used to compare the differences of speech sound errors $(52.11 \pm 25.08)$, (47.29 \pm 25.38$)$, reading skills $(3.67 \pm 1.14),(3.75 \pm 1.26)$ and writing skills $(14.61 \pm 13.49),(25.14 \pm 29.16)$ in cleft lip \& palate and cleft palate respectively, indicated that there were no differences; with $p$-value: $p=0.54,0.83,0.13$.

Conclusion: Results indicated no significant differences in speech sound errors, reading, writing skills and resonance between children with cleft lip \& palate and cleft palate.
\end{abstract}

Keywords: Cleft lip and palate, Cleft palate, Literacy skills, Orofacial clefts, Speech sound errors.

How to Cite This Article: Khan AK, Yousaf A, Tarer SA, Kausar R. The Speech Sound Errors and Literacy Skills in Children with Orofacial Clefts. Pak Armed Forces Med J 2021; 71(6): 1976-1980. D Doi: https://doi.org/10.51253/pafmj.v6i6.4044

\footnotetext{
This is an Open Access article distributed under the terms of the Creative Commons Attribution License (https://creativecommons.org/licenses/by-nc/4.0/), which permits unrestricted use, distribution, and reproduction in any medium, provided the original work is properly cited.
}

\section{INTRODUCTION}

In inherited craniofacial anomalies, cleft lip and palate is among the top five diseases worldwide. ${ }^{1}$ The incidence of cleft lip, cleft palate or both is 1 in 500 in the developing countries, and 1 in 700 live births in the United Kingdom and United States of America alone. The estimated birthrate in Pakistan is per 1000 population is $25.6 .^{1}$

Conditions related to craniofacial anomalies such as cleft lip and palate are mostly caused during development of embryo as a result when there is an interruption between fusion of labium and palatine shelves in $4-10^{\text {th }}$ week of gestation. ${ }^{2}$ Different types of clefts can be described based on the structure which is affected such as lip, alveolus, hard and soft palate. Cleft could also be unilateral (affecting right side/left side of the face) or bilateral (affecting both sides of the face). Cleft can occur in isolation such as cleft lip or cleft palate only or in combination i.e., cleft lip and palate. ${ }^{3}$

Along with the facial abnormality, there are also

Correspondence: Dr Arooj Karim Khan, Centre for Clinical Psychology, University of the Punjab, Lahore Pakistan

Received: 27 Mar 2020; revision received: 22 Jul 2020; accepted: 10 Aug 2020 other complications associated with cleft conditions such as feeding difficulties, ear infection, dental problems and psychological distress due to facial anomaly. ${ }^{4}$ Children suffering from cleft condition along with all the other difficulties also suffer from speech and language delay. The most common speech errors are articulation errors and nasal escape during speech. ${ }^{4}$

Language delay and articulation problems due to cleft could lead to poor literacy skills. ${ }^{5}$ The current study aims to find out the differences among literacy skills (reading and writing skills) in children with orofacial clefts i.e., children with cleft lip and palate (CLP) and cleft palate $(\mathrm{CP})$.

Chapman, ${ }^{6}$ in his research found that children with speech disorder due to cleft lip and palate executed poor reading abilities.

Another study conducted by the Collette et al, ${ }^{7}$ had the similar results. Results of their study showed that children with clefts scored significantly lower than controls on measures of basic reading, and phonological memory.

It can be assumed from the above literature that literacy skills (reading) might get affected by the 
speech sound errors. Some studies also tried to figure out the effect of speech sound errors on writing skills. However, in this respect very few studies were done. In 1973, Ebert and his colleagues, ${ }^{8}$ were interested to find out the difference in writing abilities of normal children and children with cleft. The results showed that cleft and non-cleft subjects appeared to be similar in their written language skills.

Kommers et $a l^{9}$ in theirresearch contradict the previous research done on same topic and revealed the differences in the written language skills i.e., children with cleft had lower percentile in written language when compared with the normative data of written language test.

Cleft lip and palate is a common orofacial malformation in newborns followed by problems related to speech, reading and writing later in school age. Currently in Pakistan there is no indigenous research available to know that what sort of speech issues the children with orofacial cleft have and how their literacy is getting affected due to that speech sound errors. So in this respect present study would give literature about difference of speech sound errors and literacy skills (reading and writing skills), in children having orofacial clefts: cleft lip and palate and cleft palate. Consequently, the literature could further be used to explore issue and their resolution related to speech sound errors and literacy skills.

Moreover, all the previous researches were done on English population and found the speech sound error pattern of English language but this is the very first study which found the speech sound error pattern of Urdu Language in children with orofacial clefts. Main hypothesis of the study was "Children with cleft lip and palate(CLP) are likely to have more speech sound errors as compare to children with cleft palate. Children withcleft palate(CP).

They are likely to have poor reading skills as compare to children with cleft lip and palate. There are likely to be differences in writing skills in children with cleft palate and cleft lip and palate."

\section{METHODLOGY}

This comparative cross sectional study was conducted at University of the Punjab, from March 2016 to February 2017) after approval from Departmental Doctoral Program Committee, Centre for Clinical Psychology (DDPC) (approval number=276) and, University of the Punjab (University approval number $=4205$ ) on March, 2016. Sample size of 210 was determined through G-Power analysis by keeping $p=0.05$, with medium effect size of 0.5 . However due to the nonavailability of participants, referral sample was confined to 42 children $(n=42)$. All these children were selected through consecutive sampling strategy from Clapp hospital, Cleft clinic and Rashid Latif hospital.

Inclusion Criteria: Children with orofacial clefts having at least average I.Q (90-109) on Solosson intelligence test revised (S.I.T-R3) and having ability to understand, read and write Urdu language were included.

Exclusion Criteria: Children who were diagnosed with cleft lip and palate due to any other syndrome such as Parry robin syndrome and/or physical disability e.g. hearing loss, physical handicapetc. were not included in the study.

Data of five children was discarded as they didn't fulfill the inclusion exclusion criteria. Prior permission was sought from the author of the measuring instruments. An informal checklist for the diagnosis of cleft condition was prepared after consulting the medical doctors who had experience of working with children having cleft issues. Two tests i.e. curriculum based measurement-written expression (CBM-WE), ${ }^{10}$ and Slosson intelligence test revised (S.I.T-R3), ${ }^{11}$ were also translated into Urdu language according to the MAP.

I guidelines to provide better comprehension to children. After translation, two sets of questionnaires were prepared. First set consisted of screening measures to recruit the participants. It included informal checklist of orofacial clefts, Slosson intelligence test revised, ${ }^{11}$ and diagnostic statistical manual-v checklist. ${ }^{12}$ Second set consisted of measuring instruments of main study which included demographic informational questionnaire, community developed VPI screener, ${ }^{13}$ word list for articulation and phonological processes, ${ }^{14}$ the annual status of education report (ASER) (Urdu literacy assessment), ${ }^{15}$ and curriculum based measurement-written expression.

Parents of participants along with their children were contacted through phone to come to the hospital for the data collection. Each child was individually screened by administration of screening tools. Children who were able to pass the screening were then tested on the second set of measurements.

For the assessment of articulation all the children were video recoded during reading of the wordlist. After the recording, every child goes through the community developed VPI screener for the assessment of resonance (hypernasality, hyponasality and nasal 
emissions). Then reading and writing task was done at the end. For the assessment of reading and writing, ASER and CBM-WE were administered respectively. In writing task, the participants were given a story starter and time span of one minute to think about the remaining part of the story. Then they were supposed to write that story in the three-minute time.

After collecting data first of all SODA analysis was done to know about the mean and standard deviations of type of speech sound errors and total speech sound errors in children having orofacial cleft. Then Data was analyzed by using Statistical Package for the Social Sciences (SPSS) version 23. The mean and standard deviation for quantitative variables and frequency and percentage were calculated for qualitative variables. The t-test was applied to see the differences in speech sound errors, reading and writing skills. Chisquare was run to see the differences inresonance (hyper nasality, hypo nasality and nasal emission) in children with orofacial clefts. The $p$-value of $\leq 0.05$ was considered significant.

\section{RESULTS}

A total of to 42 children with orofacial clefts i.e., children having CLP $(n=18)$ with mean age $11.05 \pm 2.20$ range from 8-15 years and children having $\mathrm{CP}(\mathrm{n}=24)$ with mean age $11.98 \pm 3.04$ years range from 8-16 years were selected for data collection. There were total 12 (66.7) boys and 6 (33.3) girls with CLP, 17 (70.8) boys and 7 (29.2) girls with CP (Table-I).

\begin{tabular}{|c|c|c|}
\hline $\begin{array}{l}\text { Demographic } \\
\text { Characteristics }\end{array}$ & $\begin{array}{l}\text { Cleft Lip \& Palate } \\
\text { (CLP), }(n=18)\end{array}$ & $\begin{array}{l}\text { Cleft Palate } \\
(\mathrm{CP}),(\mathrm{n}=24)\end{array}$ \\
\hline & $\mathrm{n}(\%)$, Mean \pm SD & $\mathrm{n}(\%)$, Mean \pm SD \\
\hline \multicolumn{3}{|l|}{ Gender } \\
\hline Boys & $12(66.7)$ & $17(70.8)$ \\
\hline Girls & $6(33.3)$ & $7(29.2)$ \\
\hline \multicolumn{3}{|l|}{ Family System } \\
\hline Joint & $10(55.6)$ & $11(45.8)$ \\
\hline Nuclear & $8(44.4)$ & $13(54.2)$ \\
\hline Age in Years & $11.05 \pm 2.20$ & $11.98 \pm 3.04$ \\
\hline Siblings & $4 \pm 1$ & $3 \pm 1$ \\
\hline Birth order & $3 \pm 2$ & $2 \pm 1$ \\
\hline Family income & $30388 \pm 22747$ & $19791 \pm 11549$ \\
\hline Academic Class & $3 \pm 2$ & $4 \pm 3$ \\
\hline
\end{tabular}

The mean of speech sound error of CLP children $52.11 \pm 25.08$ and CP children $47.29 \pm 25.38$ with no statistical significant difference $p=0.54$, However there was significant difference between children of CLP and $\mathrm{CP}$ on distortion $p=0.01$ which suggest that children with CLP had more distortion error as compare to chil- dren with CPthe mean reading of CLP children was $3.67 \pm 1.14$ and $C P$ children $3.75 \pm 1.26$ had no significant $p=0.83$, the mean writing score of CLP children was $14.61 \pm 13.49$ and $\mathrm{CP}$ children was $25.14 \pm 29.16$ had no significant difference $p=0.13$ shown in Table-II.

Table-III showednon-significant differences in hypernasality $(p=0.71)$, hypo nasality $(p=1.00)$ and nasal emissions $(p=0.53)$ in both groups i.e., CP and CLP. However, majority of children having $\mathrm{CP}$ were hypernasal. Two children (8.3\%) having CP were hypo nasal. Equal number of children exhibited nasal emissions from both groups.

\begin{tabular}{|c|c|c|c|}
\hline \multirow[t]{2}{*}{ Variables } & $\begin{array}{c}\text { Cleft Lip \& } \\
\text { Palate }(\mathrm{n}=18)\end{array}$ & $\begin{array}{c}\text { Cleft Palate } \\
(\mathrm{n}=24)\end{array}$ & \multirow[t]{2}{*}{$p$-value } \\
\hline & Mean \pm SD & Mean \pm SD & \\
\hline $\begin{array}{l}\text { Speech Sound } \\
\text { Errors }\end{array}$ & $52.11 \pm 25.08$ & $47.29 \pm 25.38$ & 0.54 \\
\hline Substitution & $36.72 \pm 16.57$ & $29.75 \pm 12.34$ & 1.26 \\
\hline Omission & $13.44 \pm 12.54$ & $17.42 \pm 20.08$ & 0.47 \\
\hline Distortion & $2.44 \pm 3.13$ & $0.13 \pm 0.34$ & 0.01 \\
\hline Addition & $0.06 \pm 0.24$ & - & - \\
\hline Reading & $3.67 \pm 1.14$ & $3.75 \pm 1.26$ & 0.83 \\
\hline Writing 1 & $15.06 \pm 14.54$ & $23.83 \pm 26.64$ & 0.18 \\
\hline Writing 2 & $12.72 \pm 12.86$ & $23.46 \pm 29.06$ & 0.12 \\
\hline Writing 3 & $16.22 \pm 15.59$ & $27.67 \pm 34.35$ & 0.16 \\
\hline $\begin{array}{l}\text { Average } \\
\text { Writing Score }\end{array}$ & $14.61 \pm 13.49$ & $25.14 \pm 29.16$ & 0.13 \\
\hline
\end{tabular}

Table-III: Difference of hyper nasality, hypo nasality and nasal emissions in children with orofacial clefts $(n=42)$.

\begin{tabular}{l|c|c|c}
\hline $\begin{array}{l}\text { Cleft Related } \\
\text { conditions }\end{array}$ & $\begin{array}{c}\text { Cleft Lip \& } \\
\text { Plate, }(\mathbf{n = 1 8})\end{array}$ & $\begin{array}{c}\text { Cleft Palate } \\
(\mathbf{n = 2 4 )}\end{array}$ & $\begin{array}{c}\boldsymbol{p} \text { - } \\
\text { value }\end{array}$ \\
\hline Hypernasality & $11(61.1 \%)$ & $16(66.7 \%)$ & 0.71 \\
\hline Hypo nasality & $1(5.6 \%)$ & $2(8.3 \%)$ & 1.00 \\
\hline Nasal emissions & $9(50.5 \%)$ & $9(50.5 \%)$ & 0.53 \\
\hline
\end{tabular}

\section{DISCUSSION}

In the previous literature Magnus et al ${ }^{16}$ found that children with smaller $\mathrm{CP}$ had less speech difficulties as compared to the children having more involved cleft i.e., both cleft lip and palate. Nagarajan et al, ${ }^{17}$ in their study also found similar results. Their study showed that $43 \%$ of the 129 children with CLP were having articulation and resonance disorder, while $12 \%$ of the 129 children having $\mathrm{CP}$ showed articulation problems only. However, present research revealed no difference in speech sound errors in children with orofacial clefts i.e., CLP and CP. Children in both groups exhibited speech sound errors without any difference, except children with CLP who exhibited more distortion error as compared to children with $\mathrm{CP}$. This study also found no differences in resonance i.e., hypernasa- 
lity, hyponasality and nasal air emissions. The reason may be attributed to little or no tradition of having speech therapy for improvement of speech sound errors in Pakistan. It had also been observed during data collection that parents from rural areas were not aware about speech therapy and its benefits to improve their children's speech errors and language skills.

Preceding literature such as Chapman6 in his research found that children with cleft when compared to normal children in reading skills, performed poor. Another researcher Collett, ${ }^{7}$ regarding reading skills in children with orofacial clefts suggested that children with clefts had particular difficulty in reading skills when compared with normal children.Chokbundit and Pratahnee, ${ }^{18}$ in their study found that students with CP were at risk of having age appropriate reading skills. Nonetheless, the present research revealed no differences in children with orofacial clefts. Children from both groups performed equally on reading skills. However, mean differences revealed that children with CLP have lesser score on reading skills as compare to children with $\mathrm{CP}$. Urdu is the national language and language of instruction in most government schools in Pakistan. Children may be familiar with the Urdu print and sounds at time of entering in the school, but it is not the language they have learned to speak at home. ${ }^{19}$ In current study most of the children were from Punjabi background learning Punjabi as their first language and facing the same education culture along with their anomaly; thus chances are greater to have poor reading skills.

Results also specified non-significant differences in writing skills among the children with orofacial clefts. Existing literature on writing skills have contradicted results. One research conducted by Kommers et al ${ }^{9}$ showed that children with orofacial clefts may have lower score on writing skills. However, another researcher Ebert et al ${ }^{8}$ had opposite results regarding writing skills in children with orofacial cleft. Their study showed no poor writing skills in children with orofacial clefts as compared to children without cleft. In present research although there are no differences in writing skills but mostly children from both groups performed poor. Pakistan is a developing country where conditions for education are not so well. Furthermore, in many Pakistani school young children rarely get chance to express their ideas and thoughts in written form. They are supposed to tracing the letter formation, replicating from the blackboard, and filling workbooks / sheets, ${ }^{20}$ thus resulting in poor writing ability.
This study highlights the importance of speech therapy for better speech outcomes and good literacy skills in later academic life of children with orofacial clefts.

\section{ACKNOWLEDGEMENT}

We would like to acknowledge all the participants and their parents who brought the children to the hospitals and clinics for participation. We would also like to acknowledge the authorities of health set up for their consent to conduct this research.

\section{CONCLUSION}

In conclusion there is no significant differences were found in children with CLP and CP with reference to speech sound errors except error of distortion, resonance (hyper nasality, hypo nasality and nasal emissions) and literacy (reading and writing skills).

\section{Conflict of Interest: None.}

\section{Authors' Contribution}

AKK: Conducted research in the field, collected data, write thesis, AY: Proof reading, data analysis, SAT: Guidance regarding speech variables, RK: Help in data anaysis.

\section{REFERENCES}

1. Sharif F, Mahmood F, Azhar MJ, Asif A, Zahid M, Muhammad $\mathrm{N}$, et al. Incidence and management of cleft lip and palate in Pakistan. J Pak Med Assoc 2019; 69(5): 632-639.

2. Peterson-Falzone SJ, Hardin-Jones MA, Karnell MP. Cleft palate speech. St. Louis, MO: Mosby 2016, Available at: https://www2 .asha.org/PRPSpecificTopic.aspx?folderid=8589942918\&section= References

3. American Speech-Language-Hearing Association. Scope of practice in speech-language pathology. Available at: http:// www.asha.org/ policy/(Accessed on February 10, 2020).

4. The Children Hospital of Philadelphia. Available at: https:// www.chop.edu/conditions-diseases/cleft-lip-and-palate (Accessed on February 10, 2020).

5. The Children University Hospital. The Management of Cleft lip and Palate at the children hospital temple street. 2020, Available at:https://www.cuh.ie/wp-content/uploads/2020/04/Cleft _bookFinalWeb.pdf

6. Chapman KL. The relationship between early reading skills and speech and language performance in young children with cleft lip and palate. Cleft Palate-Craniofacial J 2011; 48(3): 301-311.

7. Collett BR, Stott-Miller M, Kapp-Simon KA, Cunningham ML, Speltz ML. Reading in children with orofacial clefts versus controls. J Pediatric Psychol 2010; 35(2): 199-208.

8. Ebert PR, McWilliams BJ, Woolf G. A comparison of the written language ability of cleft palate and normal children. Cleft Palate J 1974; 11(1): 17-20.

9. Kommers MS, Sullivan MD. Written language skills of children with cleft palate. Cleft Palate J 1979; 16(1): 81-85.

10. Wright J. Curriculum-based measurement: a manual for teachers. Syracuse City Schools. Available: http:/ / www. jimwrightonline. com/pdfdocs/cbaManual.pdf. (Accessed on February 20, 2020).

11. Slosson RL, Nicholson CL, Hibpshman TH. Slosson intelligence test (SIT-R) for children and adults. Slosson educational publications, incorporated. Available at: https://www.wpspublish. $\mathrm{com} / \mathrm{sit}$-r3-slosson-intelligence-test-revised (Accessed on February 22, 2020). 


\section{Speech Sound Errors and Literacy Skills}

12. Naz H, Yousaf A, Safdar F, Dassti R, Khalid A. Diagnostic statistical manual-V checklist. Available at: https://www.nip. edu.pk/PDFs/Proceedings2016.pdf (Accessed on February 23, 2020).

13. Langman N. Community Developed VPI Screener. Available at: https://www.idmarch.org/document/Anti-aircraft+warfare/ 18iRS-show/Community+Developed+VPI+Screenerg. (Accessed on February 5, 2020).

14. Shabbir H, Zahra N. Word list for articulation and phonological processes. Available at: https://avr.tums.ac.ir/index.php/avr/ article/view/217(Accessed on February 5, 2020).

15. Annual Status of Education Report, National Assessment Survey Framework.Idara-e-Taleem-o-Aagahi. Available at: http:// aserpakistan.org/document/aser/2015/reports/national/ASER _National_Report_2015.pdf (Accessed on February 25, 2020).
16. Magnus LC, Hodson BW, Schommer-Aikins M. Relationships of Speech-Related and Nonspeech Variables to Speech Intelligibility of Children with Palatal and Lip Anomalies. Can J Speech Lang Pathol Audiol 2011; 35(1): 32-39.

17. Nagarajan R, Savitha VH, Subramaniyan B. Communication disorders in individuals with cleft lip and palate: An overview. Ind J Plast Surg 2009; 42(Suppl-1): S137-S143.

18. Chokbundit N, Pratahnee B. Oral reading problems in students with cleft palate, grades 6-8. J Med Assoc Thai 2016; 99(5): S15S20.

19. USAID. USAID funded Pakistan Reading Project. Available at: https://pdf.usaid.gov/pdf_docs/PA00TS1J.pdf (Accessed on February 27, 2020).

20. Vazir N. Developing creative writing skills in early childhood: a case study from Pakistan. J Educ Res 2009; 12(2): 17-20 . 